\title{
Stimulating Innovation: Is Canada Pursuing the Right Policies?
}

\author{
Marcel Côté and Roger Miller ${ }^{1}$ \\ Secor
}

\begin{abstract}
Based on a global survey of over 800 innovative firms, a new framework has been developed by the authors to understand innovation. Using the perspective of the innovators to explain the diversity of the strategies behind business innovation, they identified six broad patterns called games of innovation around which innovations are structured. The article points out that this framework raises significant issues about the effectiveness of current Canadian innovation policies. In light of the productivity challenges that Canada faces, which appear to be largely related to innovation, the framework also provides useful insights into future directions for public policies.
\end{abstract}

\section{RÉSUMÉ}

Sur la base d'une enquête auprès de plus de 800 entreprises innovatrices de partout dans le monde, un nouveau cadre conceptuel a été développé par les auteurs pour mieux saisir le phénomène de l'innovation. Empruntant la perspective des innovateurs, ce cadre conceptuel explique la diversité des stratégies d'innovation par la présence de six modèles ou"jeux d'innovation". L'article indique que ce cadre conceptuel soulève de nombreuses questions quant à l'efficacité des stratégies publiques d'innovation poursuivies au Canada. Compte tenus des défis de productivité du Canada et du rôle que joue l'innovation à cet égard, les "jeux d'innovation" fournissent des pistes intéressantes quant à l'orientation de ces politiques.

CANADA HAS A PRODUCTIVITY PROBLEM. The dramatic widening between Canadian and U.S. labour productivity levels is one of the most important challenges facing economists in this country. The gap, now between 25 per cent and 30 per cent in the business sector, has been increasing since 1984, when Canadian output per hour reached a historic peak of 92 per cent of the U.S. productivity level. In 2010, Canada ranked $15^{\text {th }}$ on the same indicator among the 30 OECD countries, and was in the third quartile in terms of productivity growth rates.

The causes behind this poor performance have been debated for several decades. No economic issue has garnered more attention than trying to explain why Canada lags the United States in terms of productivity growth. Underinvestment in machinery and equipment, espe-

1 Marcel Côté is a founding partner of Secor, a Montreal-based economic and business consultancy. Roger Miller is a consulting partner at Secor and past holder of the Jarislowsky Chair in the Management of Technology at the École polytechnique de Montreal. This article draws from their forthcoming book Innovation Reinvented: Six Games That Drive Growth, to be published in the spring of 2012 by University of Toronto Press. Emails: mcote@groupesecor.com; rmiller@groupesecor.com. 


\section{Chart 1}

\section{Canada-United States Difference in Growth of Multifactor Productivity (MFP), Capital Intensity and Labour Composition, Business Sector, 1962-2008 \\ (percentage points)}

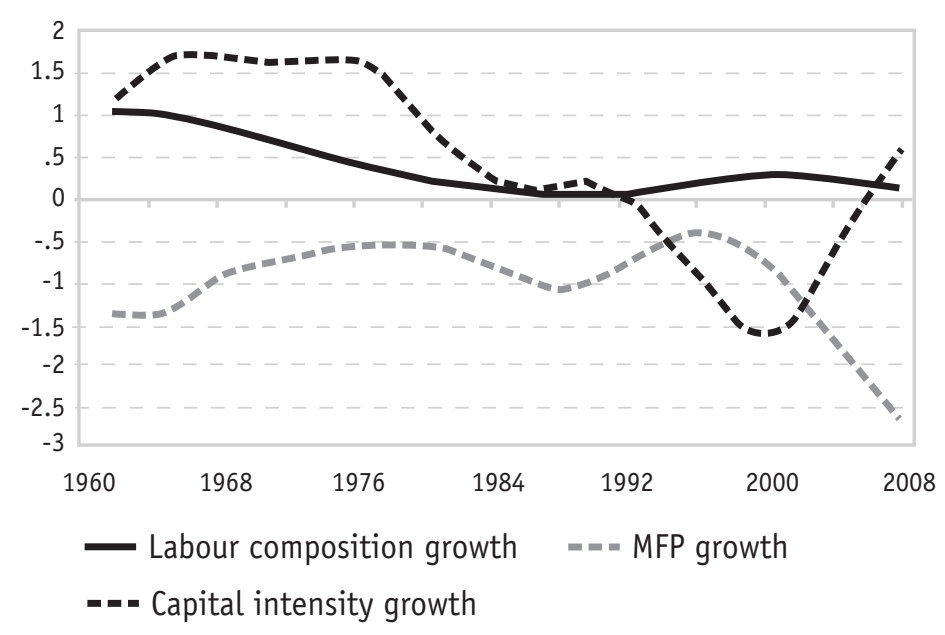

Sources: Statistics Canada; Bureau of Economic Analysis.

cially in information and communication technologies (ICTs) is often mentioned. The underdevelopment of our financial sector compared to that of the United States has been also pointed to, as well as lower productivity from self-employed business owners (Baldwin and Chowhan, 2003).

A study by Baldwin and Gu (2009) compared Canadian and U.S. labour productivity growth in the business sector over a 47 year period ending in 2008 and concluded that neither labour quality nor capital intensity can explain the widening gap. As Chart 1 shows, Canada has consistently outperformed the United States in terms of the contribution of labour quality to productivity increase. On capital intensity, Canada's performance is mixed. But except for the 1992 to 2006 period, when the Canadian dollar was well below parity, capital intensity has contributed to narrowing the gap.
As Chart 1 clearly shows, the culprit is the much maligned and poorly understood multifactor productivity, considered by many a good proxy for technological progress. Canada has scored consistently in negative territory relative to the United States on this indicator. There is a strong consensus that innovation, that is, a more effective use of labour and capital, is the prime factor underlying multifactor productivity and technological progress, or at least that component of technological progress not embodied in capital goods.

For over 50 years, our federal and provincial governments have been pursuing policies aimed at stimulating innovation. We have the National Research Council, R\&D tax credits, networks of excellence, technology transfer centres, the CANDU reactor, the Challenger jet, MaRS and so on. But these efforts, whose costs now total between $\$ 10$ and $\$ 20$ billion per year depending on the yardstick, have yet to significantly move the productivity needle.

On behalf of the federal government, the Council of Canadian Academies (2009) set up a panel in 2007 to investigate why business sector productivity growth in Canada was lagging that of the United States. ${ }^{2}$ The report concluded that the culprit, if there was to be one, was Canadian business itself, which chose deliberately not to pursue business strategies that rely on innovation, as there were easier ways of making profits. That begs the question as to whether current government policies on innovation were effective at influencing business behaviour.

That led to a second panel, known as the Jenkins panel, which reviewed federal support programs for R\&D and reported in the fall of 2011 (Government of Canada, 2011). But other than "deconstructing" the National Research Council by allocating some of its institutes to universities and pushing the others closer to

2 For a synthesis of the report see Nicholson (2009) as well as other articles from the symposium on the report in the Spring 2009 issue of the International Productivity Monitor. 
businesses, the panel's recommendations do not call for fundamental changes to the current public policy framework. They focus mostly on fine tuning current programs, and in particular, the SR\&ED tax credits. The 2012 federal budget is likely to implement most of their recommendations, albeit some with minor changes.

Will the Jenkins panel recommendations make a difference and spur more innovation in Canada? This article expresses significant reservations: Canada's public policies on innovation need a much more fundamental review if they are to impact innovation in a significant way.

\section{What We Know and What We Do Not Know about Innovation}

As defined in the Oslo manual (OECD, 2005), an innovation is the implementation of a new or significantly improved product (good or service), or process, a new marketing method, or a new organizational method in business practices, workplace or external relations. It covers everything from the introduction of insulin to that of Gillette's five-blade razor. It also includes improvements in business processes (e.g. lean production), management methods (e.g. Kaizen) and business models (e.g. Freemium pricing).

Although innovation is still much of a black box, there are several aspects on which there is general acceptance. In summary, an innovation is a product, service or a way of doing something which is superior to what existed, and which is adopted. It is different from an invention as it requires acceptance by the market and not only recognition by peers. It is also different from advancements in knowledge, as it must become embedded in a system of production and distribution. There are various types of innovation. Schumpeter popularized the concept of radical innovations that usher major technological waves that can profoundly change industrial structures, such as the automobile. The concept of disruptive innovation developed by Christensen (1997) is a related concept, capturing innovations that change the fundamental technologies of an industry. More common are incremental innovations which are improvements in products and processes that create competitive advantages without disrupting an industry.

But innovation is not the purview of only economists. Management science has taken a great interest in innovation and has greatly advanced our understanding. Among findings of interest, successful innovation typically requires more marketing than R\&D. Stimulating innovation in organizations is a cultural challenge. The role of patents has generated significant research in business and legal circles. But there is still much to understand about the management of innovation. A search on Amazon.com using innovation as a key word reveals nearly 50 thousand entries. Although this number likely includes some double counting, it nevertheless underscores the fact that innovation attracts substantial interest.

In 2000, the two of us, bringing together field experience in business and scholarly credentials, embarked upon a quest to better understand innovation. The result of that partnership is a book, Innovation Reinvented: Six Games That Drive Growth, which is being published in the spring of 2012 by the University of Toronto Press (Miller and Côté, 2012). The book represents an analysis of innovation from the perspective of the innovators, an analysis that led us to challenge many of the current public policies aimed at stimulating innovation. This article provides a synthesis of the book and presents our case.

\section{The MINE Project}

In 2000, Roger Miller launched a large scale study of innovation known as the MINE project (Managing Innovation in the New Economy) 


\section{Chart 2}

\section{The Cluster Analysis Results}

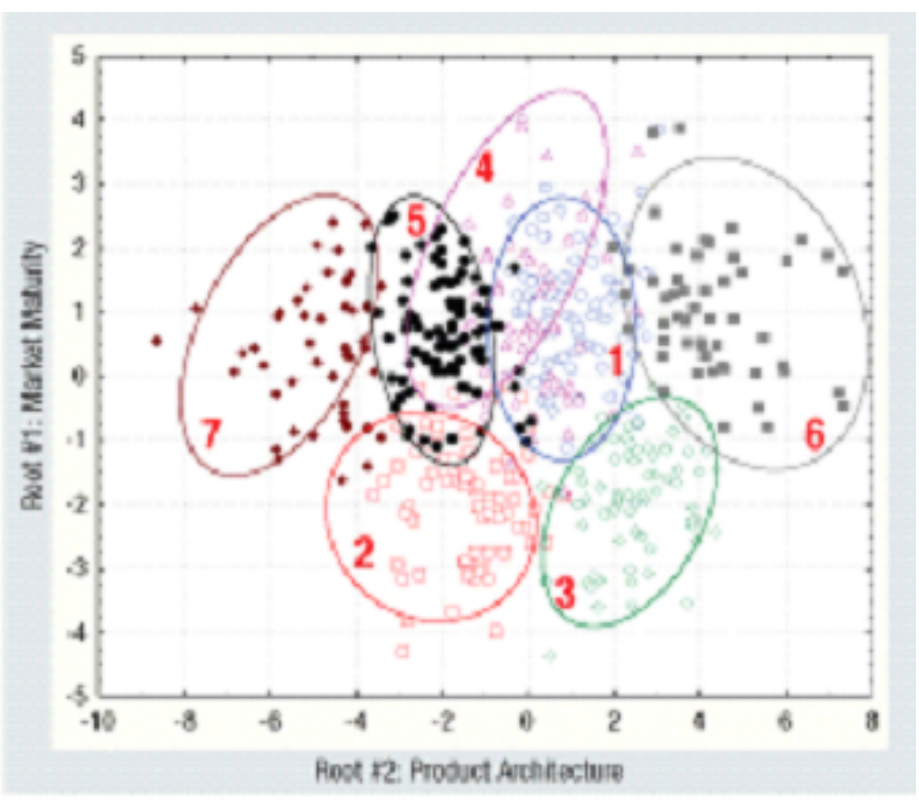

and invited Marcel Côté to sit on the Steering Committee. MINE attempted to document the diversity of innovation strategies developed in response to the changes and opportunities generated by the spread of information and communication technologies (ICT). Over 800 business organizations from all over the world responded to a detailed survey on the why, what and how of their innovation strategies. The survey was supplemented by 50 case studies of well-recognized innovative firms, from General Electric to Michelin, which were done in parallel and all of which involved interviews with at least three senior executives associated with the respondent's innovation strategies.

Making sense of the results was challenging. Extensive statistical analysis was done on the survey data. Seven clusters, shown in Chart 2, were finally identified by us. Six of them were relatively well defined by two canonical roots, which corresponded to two sets of characteristics of the business environment of the respondent firms, namely the maturity of the market and the architecture of the product they were selling. The seventh cluster grouped research agencies and consulting organizations that helped businesses innovate. They were deemed to be in the ecosystem of the innovators and were not considered in our analysis.

Identifying these two dimensions, and their ability to characterize the universe of businesses engaged in innovation was the major contribution of the quantitative analysis to our research projects. What we gradually realized was that using the innovator perspective provided a fresh look at innovation. Crossing the two dimensions yields six fairly homogeneous patterns, which we called games of innovation. We then used the fifty case studies to enrich our understanding of each game.

\section{The Innovation Game Framework}

The diversity of the patterns of innovation, from insulin to the five-blade razor, has always puzzled researchers. The six games defined by crossing the two dimensions addressed this issue: not only is a game associated with a particular business context, but it also calls for a specific set of innovation strategies. In other words, broken down into six games, the diversity of the innovation experience is much better understood.

\section{Maturity of a Market: Two States - Emerging and Mature}

In an emerging market, from the time an invention is first commercialized successfully, becoming an innovation, to the time the product (or service) has reached most of its potential customers, a market is characterized by a continuous flow of innovations, some big, some small, as the product is refined and improved upon. The market is characterized by rapid growth, and initially supports the entry of numerous emulators. 


\section{Table 1}

\section{The Six Games of Innovation}

\begin{tabular}{l|c|c|c|c|}
\multicolumn{2}{c|}{} & \multicolumn{3}{|c|}{ Product (and Service) Architecture } \\
\cline { 3 - 5 } & Stand alone & Open system & Closed system \\
\hline \multirow{2}{*}{ Market Maturity } & Emerging & Eureka! & Battle of architecture & System Breakthrough \\
Sespresso & Smart Phone & Early ERPs \\
\cline { 2 - 5 } & Mature & $\begin{array}{c}\text { New and Improved } \\
\text { Tide Detergent }\end{array}$ & $\begin{array}{c}\text { Mass Customization } \\
\text { Wal Mart }\end{array}$ & $\begin{array}{c}\text { Pushing the Envelope } \\
\text { TGV }\end{array}$ \\
\cline { 2 - 5 } & & &
\end{tabular}

After 10 to 15 years, when the market approaches maturity, a rapid consolidation is generally seen, as a few winners emerge. (In Chart 2, clusters 1, 2 and 3 group the organizations active in emerging markets and clusters 4 , 5 , and 6 mature markets.)

In a mature market, starting some twenty years after the market has emerged, the customer base becomes saturated. Innovation is much more paced, as competitors try to differentiate their products and lower their costs, fighting for the same customers. Growth has tapered off to the general rate of the economy.

\section{Product Architecture: Three States - Stand-alone, Platform-based Open System, Closed System}

Many products are dependent on other products to deliver their benefits. An airplane engine is part of a closed system, integrated into a plane. A Facebook application requires the Facebook platform to deliver its benefits, but the platform is open and can accommodate a wide range of applications. A stand-alone product such as the classic mouse trap is not constrained in its innovation strategies. Architecture is a major determinant of innovation strategies. (In Chart 2, clusters 1 and 4 were associated with stand-alone architectures, clusters 2 and 5 with closed systems and clusters 3 and 6 with open systems.)

The combination of these two dimensions gives rise to six games, as Table 1 illustrates. At any given time, a market is characterized by one game, which defines how market participants will approach innovation. Each game also calls for specific competencies.

The evolution of the smartphone market over the years can illustrate the concept of a game, in that instance a battle of architecture. The smartphones game started in 1997, when Research in Motion (RIM) introduced a pager that transmitted e-mail instead of phone numbers. Emulators sprang up rapidly, but flush with cash from its 1998 IPO, RIM took a strong early lead. The Blackberry with the scrolling wheel on the side came out in 1999. In 2002, RIM managed to add the telephone function, a breakthrough that allowed texting and which progressively brought most of the mobile telephone manufacturers in the market as competitors, and gave rise to the development of a consumer segment in what had been mostly a business market. Many small improvements were progressively added as a continuous flow of new models were launched. Then, in 2007, Apple launched the iPhone, adding design and much improved Web functionalities. The entry of Apple accelerated the wave of small innovations as competitors reacted and adjusted. In 2009, Google launched its Android platform; determined to capture a big share of the market, it chose to license it at no cost. Within three years, it had captured 50 per cent of the North American market, making it a highly profitable product for Google as it reaps advertising revenue. 
Market growth is still rapid, above 10 per cent per year in North America, and leaping by up to 50 per cent a year in developing countries. RIM is still there, no longer the market leader, but with a strong franchise in the business segment. But growth will taper off in five or six years, as market penetration crosses the 50 per cent mark and most people who want a smart phone will have one. By that time, the global market will be dominated by a handful of players. The design will also have stabilized, and innovation will change allure.

Here is a quick review of the six games.

Eureka!: Recognizing the commercial potential of an invention, the genesis of an Eureka! game, emulators flock into the emerging market, improving the product rapidly through their individual contributions, as the market grows rapidly. The single cup coffee machine market is typical of an ongoing Eureka! race that has still not hit maturity. Attracting first-time customers is the name of the game, putting a strong emphasis on marketing and product management. Agility and the ability to manage rapid growth are essential. As growth eventually tapers off, distribution becomes critical, crowding out smaller players, and the market consolidates around a limited number of competitors.

New and Improved: As a classic product in that game, we use Tide's popular slogan to name the game, which is the most common of all the games of innovation. In this game, the innovation is almost always incremental and can bear on the product, on the processes, and from time to time, on the business model. The game dominates industrial markets (from paper to iron ore), consumer markets and in many services. To play in the game, an organization has to choose innovation as a strategic thrust, which many don't do. Innovative companies in this game are characterized by a strong change-oriented culture and by the integration of the pursuit of con- tinuous improvement in their business processes.

Battle of Architecture: Characterized by multi-sided markets, this game is "orchestrated" by emerging platforms that form coalitions of developers and distributors, and which compete with each other to attract customers with an open set of benefits. The smartphone and social media markets are typical of such a battle. Network effects ("the more, the better") are critical in this game. Aggressive marketing and pricing policies are generally required early in battles of architecture to rapidly reach the threshold of customers that will kick in network effects. As a consequence, the best product does not always win, as the classic VHS-Beta battle taught us three decades ago. Also critical in this game is coalition management, an art in itself in these markets, as Steve Jobs, a master in that regard, has shown. Battles of architecture are characterized by rapid consolidation, very early in the game, as also-ran platforms are rapidly forgotten. This game is increasingly frequent in the internet world, where platforms abound.

Mass Customization: Mature platforms engaged in mass customization are found mostly in mass retailing and in complex products such as the automobile. The orchestrator of the platform offers a wide selection of benefits to its customers, as demand is increasingly segmented (customized). Innovation bears on the underlying systems, which have to be continually improved, and on the modules (products, components, etc.) that are attached to the platforms, and which must be continually renewed. Best practices bears on managing the evolution of the basket of benefits while keeping the integrity of the system's brand (from Walmart to Toyota) that encapsulates the promise to the customers. Managing the network of suppliers, and keeping them innovative, is also a critical skill.

System Breakthrough: This game starts with a deep-pocket customer who faces a major prob- 
Table 2

Contribution of Innovation Games to Economic Growth

\begin{tabular}{l|c|c|c|c|c|} 
& \multirow{2}{*}{$\begin{array}{c}\text { Share } \\
\text { of GDP }\end{array}$} & \multicolumn{4}{|c|}{ Contribution to growth through innovation } \\
\cline { 3 - 6 } & $10 \%$ & Stand alone & Open system & Closed system & Total \\
\hline Emerging market & $10 \%$ & $\begin{array}{c}\text { Eureka! } \\
\text { architecture } \\
15 \%\end{array}$ & $\begin{array}{c}\text { System } \\
\text { Breakthrough } \\
5 \%\end{array}$ & $35 \%$ \\
\hline Mature markets & $90 \%$ & $\begin{array}{c}\text { New and Improved } \\
30 \%\end{array}$ & $\begin{array}{c}\text { Mass Customization } \\
20 \%\end{array}$ & $\begin{array}{c}\text { Pushing the Envelope } \\
15 \%\end{array}$ & $65 \%$ \\
\hline Total & $100 \%$ & $45 \%$ & $35 \%$ & $20 \%$ & $100 \%$ \\
\hline
\end{tabular}

lem or bottleneck, and who partners with an organization to develop the solution. Such a call is what gave birth to great companies such as SAP and Microsoft, the first one "inventing" the ERP software, the other one developing one of the first operating systems for personal computers. Success usually rests on strong collaboration between the determined customer (ICI and IBM in the two examples above) and the solutions provider, as budget overruns and extensive delays are likely to strain the partnership. Another important factor for these games to develop is the ability of the solution provider to commercialize the breakthrough to other customers, competing with smart emulators that step in to offer similar solutions.

Pushing the Envelope (PTE). The counterpart of system breakthrough in mature markets, PTE games are fuelled either by customers' ambition and ego or by their strategic decision to develop a sustained competitive advantage. The customers call upon "experts" to help them develop innovative projects that redefine the state of the art. Building a new generation of TGV, the tallest building in the world, the most advanced airport, or a large infrastructure project that pushes the limits of the state of the art, are typical PTE manifestations. So are the large innovative information-based business systems, often coupled with major capital investments, that allow organizations to leap ahead of their competitors.
No game is eternal. Game transitions, brought on by either market maturity or by fundamental technological waves, are often encountered, destabilizing the existing order. Incumbents are often short-changed during these transitions as they are run by people that do not have the right skills and competencies to succeed in these new games. The traditional telecom market was destabilized in the 1990s as the internet arrived and mobile communication spread. The telcos offer a good example of the challenges involved. In the 1980s, they were among the largest companies in the world, and many of them sought to diversify out of their basic mature businesses. Then, right on their own networks, the trillion dollar internet industry developed. Despite their huge cash flows and access to the best consultants and investment bankers in the world, not one of the telcos was able to enter the internet business in any significant way. The internet space is now dominated by companies started since then while telcos are increasingly confined to the transportation of kilobits, a commodity business if ever there was one.

\section{Growth Accounting}

The footprint of the emerging markets, where new products grow rapidly, is much smaller than commonly believed, as Table 2 shows. The internet economy, including the e-commerce activities at their retail income value, represents 
about 4 per cent of GDP (Pélissié du Raussas, 2011). The ICT-production activities, which partly overlap the internet economy, also represent around 4 per cent of GDP (Donahoe et al., 2010 and BEA, 2011). Life science as a sector is around 1 per cent of GDP. We estimate that emerging markets, defined as those activities that are growing at three times or more the rate of the overall economy (and on the average, at five times), are contributing at most 10 per cent of GDP. The rest is made up of mature markets.

Our estimates of the contribution of the industries engaged in each game to the overall contribution of innovation to technological progress suggest that emerging markets represent only one third of it, the rest coming from mature markets. We should also point out that the stand alone games are dominant in sectors that are estimated to represent about 45 per cent of the value added in the economy. However, as ICT spreads, we should expect open system games, now dominant in about a third of the economy, to increase in importance.

\section{Identifying Levers for Public Policy}

The quest to understand why and how businesses pursue innovation led us to ask how public policies can affect their behaviour. Which policies can best lever innovation in business? Before addressing this question, here are some of the lessons for public policy that stem from the games-of-innovation framework

- Innovation rests first and above all with a decision by a business to pursue an innovation strategy, as the Council of Canadian Academies panel on business productivity had also concluded in 2009. Pursuing innovation is inescapable in emerging markets, where a business that does not innovate is bound to fail rapidly. But in mature markets, it is another story. A majority of businesses and indeed, of all organizations, as we can include governmental and municipal, university, school, and health (MUSH) organizations, do not incorporate innovation into their strategies, at least beyond lip service. ${ }^{3}$ A starting point for any innovation policy is to find the proper levers that will induce businesses in mature markets to incorporate innovation in their strategies.

- In mature markets, the second most important factor for a business to innovate, beyond a strategic commitment to innovation, is a corporate culture whose dominant trait values continuous improvement in products and process and supports organizational change. Innovative organizations take innovation seriously. It shows in their culture and in their acceptance of change, generally structured by a customer orientation focus. In emerging markets, the most important competencies to succeed are marketing and product management, followed by agility and managerial ability to cope with rapid growth. How public policies affect such variables is an important issue.

- Paradoxically, R\&D is not on the list of the principal drivers of innovation. Although it is associated with a large proportion of innovations, it is seldom a critical factor. In both emerging and mature markets, the vast majority (over 95 per cent) of innovations involve improvements to what exists in the market or in the production process. It may require some $R \& D$, but the most critical factors in the success of an incremental innovation is the decision of what to do and how to market it if it is a product, or how to implement it if it is a process improvement.

3 Booz \& Co. surveys annually the thousand businesses that do the most R\&D globally. Even among these businesses, only half make innovation a meaningful element of their business strategy. We assume that this proportion is even less for other organizations. See Jaruzelski, Loehr, John and Holman (2006). 
The $\mathrm{R} \& \mathrm{D}$ component is generally a mundane task in this process. This explains why $\mathrm{R} \& \mathrm{D}$ intensity is poorly correlated with innovation performance. 4

- A big exception to the previous statement is in closed system games (System Breakthrough and PET), where ambitious customers hire experts and challenge them to develop breakthrough solutions or push the envelope beyond current solutions. R\&D is often at the core of the projects undertaken in these games, and they can be made more attractive through risk-sharing policies. That approach is one of the mainstays of the DARPA (Defense Advanced Research Projects Agency) strategy in the United States. The approach is increasingly popular with governments in most industrial countries as part of their advanced technology development strategies, in areas such as space, transportation material, energy production and green energy.

- The original inventions (or breakthrough innovations) that give rise to an emerging market, such as the first smartphone, the first social network, the first personal watercraft or a new chemical process, are few compared to the thousands and thousands of innovations that follow in the wake of the market-creating innovation. Furthermore, the innovator/inventor behind most breakthrough innovations does not generally survive more than a few years in the industry, pushed aside by smarter and more competitive emulators that rapidly improve the original ideas. From an industrial policy point of view, supporting a good emulator is much more productive that supporting a "breakthrough innovator". The pharmaceutical sector is an exception to this general rule, as most innovations in this sector are subject to stringent regulation that not only slow down the pace of development of any innovative product and of its emerging market, but also limit the entry of emulators, which just compounds the inertial impact of regulation.

- Innovations result from the integration (or grafting) of new ideas onto existing products and processes. These ideas can come from a wide range of sources: customers, employees, suppliers, competitors, internal R\&D and increasingly, from "out there". Open innovation is the biggest trend in the realm of innovation now, being embraced by the most innovative companies such as Procter and Gamble and General Electric. On the other hand, universities are seldom mentioned as a source of ideas, except in closed system innovation projects where universities based experts are asked to collaborate on.

- The major contribution of universities to innovation is not their research, but the graduate students that are hired by innovating companies and who can absorb leading edge knowledge and integrate it in their processes and products. University research is important, but its main contribution is to the advancement of knowledge, which is diffused in the global commons of ideas. Some of it may come back in some form or other to businesses, as ideas and concepts that are integrated in improved products and processes, and in relatively few instances, ideas and concepts that result in a new product or service that creates a new market and start a new game. On the other hand, well trained and talented individuals graduating from a local university who decide to stay in the region, and who can identify good ideas in

4 Analysing their data base of global technology intensive businesses, Booz \& Co. found that R\&D intensity was not correlated with indicators of innovation performance such as 5-year sales growth, profitability, profit growth and return on capital. See Jaruzelski et al. (2006). 
the global commons, are highly sought by fast growing businesses.

- Intellectual property (IP) is important in the innovation process. But patents, a key provider of IP, do not play the critical role that is commonly assumed, as they are awarded too late in the process, when the critical commercial battles have been fought. Patents can generate significant revenues. But with the exception of some highly regulated sectors such as life sciences, they provide little protection to an innovator when it matters, that is in the months following the market introduction of the innovative product or the installation of a new process. This is a period when emulators swarm around the innovator and his innovation, and not only copy it, but improve the features of the product or process. Brands, copyrights and good old secrecy are much more useful during these critical moments when a product or a process becomes public. In the smartphone and tablet markets for instances, new products are reverse-engineered within a few days of their launch. An innovator must ensure that these innovative products are commercially successful in their most important first few years of production and are protected from copycats and their cheaper prices. Copyrighted brands and to a lesser extent, jealously guarded production secrets, give that protection. Recent patent skirmishes between Apple and Google and its surrogates had little to do with innovation and reflected the hard-ball competitive tactics between two global platforms. ${ }^{5}$

The "games of innovation" framework facilitates the identification of what matters to foster innovations. What it does first and foremost is to place innovations in their real world context, which is usually within a continuous stream of improvements in products and processes, with an occasional breakthrough that gives rise to a new market or disrupt an existing one. An effective set of public policies aimed at stimulating innovation should target the continuous stream of improvements.

\section{Current Public Policies}

Many of Canada's current public policies to stimulate innovation do not fare well under the games-of-innovation framework. This section reviews the most important of these policies, grouped into four categories that integrate both federal and provincial initiatives.

\section{Tax Support for Industrial R\&D}

Costing about $\$ 5$ billion per year in Canada, or $1 / 3$ of 1 per cent of GDP, the highest among the OECD countries, tax credits reduce the cost of $\mathrm{R} \& \mathrm{D}$, one of the factors, although rarely the most important, behind most innovations. For instance, in emerging markets, marketing and distribution costs of "new" products are generally more important than $R \& D$ spending. Although reducing the cost of one factor reduces the overall cost of the innovation, to what extent is $R \& D$ the best cost lever in emerging markets? A more basic question is whether cost reduction is a good lever in an emerging market, as competition demands that a firm innovate or perish. R\&D costs are usually not central to the strategic decisions that shape what and when the firm will launch an improved product, compared to time to market, marketing and distribution issues, and competitive activities. The same questions can be asked in mature markets, where $\mathrm{R} \& \mathrm{D}$ tax credits are specially prized by $R \& D$ intensive firms, which often have become hooked on these injections of cheap capital. But are they better innovators in return? Or does the low cost of R\&D bring them to support marginal projects that are $R \& D$ and tax credit intensive?

5 Indeed, Google's response to patent threats by Apple was to buy the Motorola's rich portfolio of patents and use it to convince Apple to discuss a cross-licence deal. 
Most countries that provide financial support for business innovation have not espoused tax credits for R\&D. Most countries offer subsidies on the cost of whole projects that meet certain criteria, similar to the National Research Council's Industrial Research Assistance Program (IRAP), which costs about $\$ 250$ million a year and targets small and medium sized businesses. Such an approach probably entails more bureaucracy, but also more selectivity toward innovations that matter and less bias toward R\&D intensive innovation.

\section{Financing Research Conducted in Universities and in Dedicated Research Centers}

This type of support, which includes National Research Council intra-mural research and provincial programs, is estimated to cost around $\$ 5$ billion per year and is related to both basic and applied research. Most of this research contributes to advancements of knowledge. Little of it is tied to actual innovation games, where time, secrecy and agility are essential. In fact, this research is the core of Canada's Science and Technology policy and has little to do with an innovation policy. By all indications, Canada is performing well on this research. On a per capita basis, it is among the top two or three leading countries in the world in terms of the quality and influence of its research (Council of Canadian Academies, 2008). But the results of this research go into the global commons of knowledge, where they represent a relatively small contribution to a global endeavour. Innovators find many ideas in that global commons, but at that stage, the Canadian component is fused with the rest. The link of Canadian research to Canadian innovation is weak at best.

\section{Sector and Project Specific Industrial Support}

Provided as loans, matching grants, and defence procurement offsets, this type of support targets projects in selected sectors deemed "strategic": aerospace, defence-related technologies, shipbuilding, pulp and paper, energy, etc. Provinces run small programs in this category, but most of the money is federal, to the tune of $\$ 1$ billion a year when everything is added up. Big ticket items and large businesses are mostly involved, though small and medium size suppliers also benefit. Most projects that are supported are involved in closed system games, such as a new plane or a new large scale software system. Such support can significantly reduce the risks associated with pushing the envelope innovation projects and thus can stimulate business to invest in innovations in sectors judged strategic for Canada. Most countries are involved in that type of assistance.

\section{Regionally Focused Assistance and Cluster Support}

This assistance and support can take many forms, from research subsidies to tax assistance for venture capital and training grants. The goal of replicating Silicon Valley underlies many of these policies. Fortunately, because actual entrepreneurial success is typically one of their building blocks, these policies can indeed strengthen clusters, giving Canada its Technology Triangle, its Silicon Valley North, MaRS, video games in Vancouver and Montreal, optics in Quebec City, etc. However, much of the funding channelled by the regionally focused policies ended up supporting institutional research, and the same comment raised in the previous section about the lack of relation of that research with the innovation process applies.

But this support contributes to the creation of a business environment conducive to innovation. Access to talents and spin-offs in early 
emerging market games are two critical elements for innovation that the games-of-innovation framework draws attention to. Technology-oriented graduates from local universities are important for fast-growing firms in technological sectors, for specialized firms in the ecosystems of large innovative firms and for their new innovative projects. These graduates, who for all kinds of downto-earth reasons, have a local bias when they seek employment upon graduation. The placement of their graduates in local firms represents the most important contribution of universities to Canada's innovation performance. Spin-offs, which rely on venture capital, models and pioneering customers are also stimulated by the environment of dynamic clusters. In that regard, the activities of the Business Development Bank and various provincial programs targeting high-potential high-risk entrepreneurial ventures are a positive contribution to innovation. But Canada's innovation problem is much bigger than anything that could flow from the entrepreneurial effervescence in the technology field. VCsupported firms represent a narrow segment of the business population.

\section{The Will to Innovate}

None of the above policies effectively tackle the 25-30 per cent gap in Canada's labour productivity level relative to that of the United States. This gap seems to stem not from labour deficiencies and not from a lack of investment, but from the willingness of Canadian business at large to innovate, and develop or adopt superior solutions in their market. Could better competition policies stimulate profitable but complacent Canadian businesses in mature sectors (mostly in services), prodding them to be more innovative? They are the cause of the poor productivity figures of Canada. Can more interregional and more international competition force them to be more innovative, to improve their processes and to differentiate their products? That debate does not really take place in Canada, as it is too often mired in federal-provincial or protectionist squabbles. But there is no doubt that in mature markets, the decision to compete on the basis of differentiated products and of improved processes is the prime driver of innovation strategies.

\section{Better Public Policies}

The assessment of Canada's public policies on innovation by filtering them through the gameof-innovation framework raises numerous questions about their effectiveness. Most of the money currently goes to tax credits for industrial $\mathrm{R} \& \mathrm{D}$ and to academic research that may contribute significantly to the advancement of knowledge, but which is not tied to the actual innovation process. This passive but generous promotion of research in universities and in business is a relatively inefficient way of promoting innovation. Industry and project-specific support and regionally focused assistance received much less funding, but are more efficient levers. A broadening of demand-side sector-specific support policies (à la DARPA), common in the United States, Europe and Japan, would be a positive development.

Regionally-focused strategies, with their emphasis on talent development and on entrepreneurial initiatives, can also foster pro-innovation attitudes in local businesses, leading them to invest more in innovation strategies then they would otherwise, making them more active players in whatever innovation games they are involved. Programs that encourage local employment of university graduates could have similar effects. Restructuring the National Research Council along the recommendation of the Jenkins panel, ensuring that some of its institutes work more closely with business, is also likely to represent a more effective use of their 
research capacity. But again, leveraging $\mathrm{R} \& \mathrm{D}$ has limited impact on the overall innovation strategies of most businesses. Finally, both federal and provincial governments have policies to stimulate venture capital. Part of it targets startups in emerging markets, which is good in itself, but given the low probability of the long-term survival of these firms and the small footprint of emerging markets in the total economy, the impact is somewhat limited. Venture capital that targets firms that thrive in the ecosystems of innovators and non-technological businesses is likely to have a greater impact as the odds of survival is higher and their footprint in the economy larger.

Other policies may be made part of a national innovation strategy. Let's consider the ownership of a rapidly growing Canadian business that becomes as a significant player in an emerging market. For instance, should the Investment Canada Act be used to stop a take-over of RIM, if such an event ever occurs? Would it have been a positive development if a Japanese snowmobile manufacturer had taken over Bombardier in 1980, before its diversification into business jets and rail transportation? These are questions which the development of an innovation policy should address.

But a more fundamental observation is the limited leverage that governments have to stimulate innovation. Most business innovations stem from corporate decisions. The cost of developing improved products or processes is a secondary element in such decisions, which bear mostly on the what, when and how to market it, usually as a competitive response. The decision to respond to the competition through an innovation is the fundamental step, and that decision depends on the alternatives and on corporate culture. It is worthwhile investigating whether in Canada, as a general rule, the business environment is characterized by the triple combination of less competitive pressure, more alternatives to innovation and a culture of comfort that does not pressure management to assume the uncertainty of innovation. How can government policies influence these three factors is something we should also ponder. Reducing the cost of innovating through tax credits is probably not very effective. Luring businesses to undertake innovative projects through specific risk-sharing subsidies, as many countries do, is probably more effective, but one has to accept the process, which most Canadians seem reluctant to do.

Governments are also lured by the appeal of breakthrough innovations and by the excitement of new markets, trying to build the next Bombardier (which came out of the snowmobile market) or the next RIM, which is coming out of the emerging smartphone market. But from a public policy point of view, successes in emerging market games are long shots: over a 20 year period these markets grow at frantic rates, and most entrants (and there are quite a few early in the game) will disappear, either by being taken over or through bankruptcy. There were probably more than 20 PC manufacturers launched with great hopes in Canada in the early 1980s, many with the strong support of governments. None survived. Indeed, only a few survived in North America. In biotech, after twenty years during which governments invested several billions of dollars every year to subsidize research in business and universities, there is one Canadian pharmaceutical/biotech company with a market capitalization above one billion dollars, and six with market capitalization between $\$ 1$ billion and $\$ 100$ million. ${ }^{6}$ Moreover, employment in the more mature side of the pharmaceutical

6 As of March 15th 2012, Valeant has a market capitalization of $\$ 16$ billion. The others are Paladin (\$851 million), QLT (\$369 milion), Oncolytics (\$356 million), YM (\$233 million), Theratechnologies (\$150 million), and Cangene (\$127 million). 
industry is down, and so is industry $\mathrm{R} \& \mathrm{D}$. The subsidized research may have been quite useful, but it did not translate into innovations and into economic development. That is how challenging emerging markets are.

The game of innovation framework introduces a new perspective to the development of innovation policies by bringing forward the business context which is actually taken into account when decisions to innovate are taken. The development of public policies on innovation will benefit by incorporating this framework into the analysis.

\section{References}

Baldwin, John R. and Chowhan, James (2003) "The Impact of Self-employment on Labour-Productivity Growth: A Canada and United States Comparison," Statistics Canada, Micro-economic Analysis Division, Research Paper, Cat. No. 11F0027MIE - No. 016.

Baldwin, John and Wulong Gu (2009) Productivity Performance in Canada, 1961 to 2008: An Update on Long-term Trends, Statistics Canada, Cat. No. 15-206-X No. 025, Ottawa, 2009.

Bureau of Economic Analysis (2011) Information Technology Outlook, Washington.

Christensen, Clayton M. (1997) The Innovator's Dilemna, (Cambridge: Harvard University Press).
Canadian Council of Academies (2008) 2005 Assessment of the State of Canada Science and Technology, Ottawa.

Council of Canadian Academies (2009) Innovation and Business Strategy; Why Canada Falls Short, Report of the Expert Panel on Business Innovation, Ottawa.

Donahoe, Matthew M., Edward T. Morgan, Kevin J. Muck, and Ricky L. Stewart (2010) Annual Industry Accounts: Advance Statistics on GDP by Industry for 2009 and Revised Statistics for 19982008, Bureau of Economic Analysis, Washington, June.

Government of Canada (2011) Innovation Canada: A Call to Action, Expert Panel Report, (Jenkins report).

Jaruzelski, Barry, John Loehr, John and Richard Holman (2006) Smart Spenders: The Global Innovation 1000, Booz \& Co.

Miller, Roger and Marcel Côté (2012) Innovation Reinvented: Six Games that Drive Growth, (Toronto: University of Toronto Press).

Nicholson, Peter (2009) "Innovation and Business Strategy: Why Canada Falls Short," International Productivity Monitor, Number 18, Spring, pp. 5171.

OECD (2005) The Measurement of Scientific and Technological Activities: Proposed Guidelines for Collecting and Interpreting Technological Innovation Data, (The Oslo Manual), Paris.

Pélissié du Raussas, Matthieu (2011) Internet Matters: the Net's Sweeping Impact on Growth, Fobs and Prosperity (New York: McKinsey Global Institute). 